\title{
Philosophiques
}

\section{Figures de l'empirisme. Discours de réception à la Société Royale du Canada \\ Présentation}

\section{Josiane Boulad Ayoub}

Volume 12, numéro 2, automne 1985

URI : https://id.erudit.org/iderudit/203293ar

DOI : https://doi.org/10.7202/203293ar

Aller au sommaire du numéro

Éditeur(s)

Société de philosophie du Québec

ISSN

0316-2923 (imprimé)

1492-1391 (numérique)

Découvrir la revue

Citer ce document

Boulad Ayoub, J. (1985). Figures de l'empirisme. Discours de réception à la Société Royale du Canada : présentation. Philosophiques, 12(2), 411-411.

https://doi.org/10.7202/203293ar d'utilisation que vous pouvez consulter en ligne.

https://apropos.erudit.org/fr/usagers/politique-dutilisation/ 


\section{FIGURES DE L'EMPIRISME \\ DISCOURS DE RÉCEPTION À LA SOCIÉTÉ ROYALE DU CANADA}

\section{PRÉSENTATION}

Il nous est apparu important, autant pour la vie de la pensée que pour saluer l'une des figures intellectuelles dominantes de notre communauté philosophique, de faire bénéficier les lecteurs de Philosophiques du discours prononcé par M. François Duchesneau (Université de Montréal) le 7 décembre 1984, lors de sa réception au sein de la Société Royale du Canada, comme membre de cette prestigieuse institution, la plus ancienne de nos sociétés savantes. Le devenir intellectuel du récipiendaire se dessine, de manière éloquente à même les pages qu'on va lire, qui retracent avec la sûreté et la précision propres au discours incisif de François Duchesneau les "Figures de l'empirisme ». On sait que ce sont les problèmes posés par cette " philosophie si peu philosophique " qui ont surtout retenu la patiente attention du nouveau sociétaire.

Philosophiques est heureuse, en publiant cette réflexion*, de pouvoir souligner ainsi la reconnaissance et l'estime dans lesquelles ses pairs tiennent M. François Duchesneau. Les preuves quotidiennes abondent de l'excellence de son travail de recherche ainsi que de l'efficacité avec laquelle il accomplit son rôle institutionnel dans la diffusion et la reconnaissance de l'esprit philosophique dans notre société et dans nos institutions.

\section{Josiane Boulad Ayoub, Directrice-adjointe.}

\footnotetext{
* L'autorisation de publier ce texte nous a été aimablement donné par la Société Royale du Canada. Il paraîtra dans un numéro de Présentation, organe officiel de la Société, au cours de l'automne 1985.
} 